\title{
Does the lending rate impact ETF's prices?^
}

\author{
Alan De Genaro* \\ Marco Avellaneda**
}

\begin{abstract}
In this paper we develop an econometric model to empirically test the hard-to-borrow model of Avellaneda and Lipkin (2009) where asset prices jump as result of "buy-in" procedures. The model is estimated using an extended version of simulated maximum likelihood (SML) for a selected group of Leveraged ETF, because these instruments have been sporadically hard-to-borrow and are liquids. In general we do not find enough statistical evidence supporting that hard-to-borrow effect impacts LETFs. On the other hand, we do find statistical significance supporting the presence of jumps for all Leveraged ETFs in our sample.
\end{abstract}

Keywords: hard-to-borrow, leverage ETF, simulated maximum likelihood, jumps

JEL Codes: G12, G23, C15

\section{Introduction}

Securities lending is a financial transaction through which, for an agreed fee, holders of securities (lenders) authorize their transfer to a third party (borrower). The borrower is free to sell such securities or use them for any other purpose, for instance fulfill an obligation to deliver securities for the aim of settling another transaction. A frequent trading strategy which is linked to securities lending transactions is short-selling, in which investors borrow a stock to sell it, aiming to make a profit on its decline.

In general, a securities lending transaction is performed over-the-counter (OTC), where borrowers and lenders bilaterally agree the terms. In many

Submitted on 14 August 2014; Reviewed on 02 October 2018

$\star$ The authors would like to thanks Milton Barossi-Filho, Rodrigo De-Losso and two anonymous referees for very useful suggestions. For comments we are indebted to numerous seminar participants at $34^{\text {th }}$ Meeting of Brazilian Econometric Society and FEA/USP for theirs comments. Alan De Genaro gratefully acknowledges the financial support of B3 and Courant Institute for its generous hospitality during the period that part of this research was conducted. Any remaining errors are our own.

* Getulio Vargas Foundation, FGV/EAESP.

** Courant Institute of Mathematical Sciences, NYU

$\boldsymbol{\nabla}$ alan.genaro@fgv.br $\boldsymbol{\nabla}$ avellane@cims.nyu.edu 
countries, among them the USA, custodian banks that clear and hold positions for large institutional investors have been the largest equity lenders, which with the beneficial owner's permission, they can act as lending agents for the beneficial owners by lending shares to borrowers. On the other side, the largest borrowers of stocks are brokerage firms facilitating the short demand for their own proprietary trading desks, for their hedge fund clients, and for any other investors. A common practice performed by brokerage firms to facilitate retail short sales involves borrow directly stocks from the accounts of their own customers.

In practice, when an investor places an order to sell short, the brokerage firm checks to make sure that the shares are available for lending. This is usually done by consulting a hard to borrow list, which provides an up-to-date catalog of securities used by brokerage firms to indicate what securities are difficult to borrow for short sale transactions. If the stock is not on the list, then the brokerage firm assumes that shares can be easily obtained and proceeds with processing the short sale order and by doing so the brokerage firms comply with regulation of the affirmative determination requirement for short sales. ${ }^{1}$

A feature embedded in the majority of all securities lending transactions is the right to terminate a stock loan at any time. ${ }^{2}$ The recall right embedded in securities lending transactions allows the stock lender's to recall the shares at any time before the contract ending without any rebate been paid to the borrower. If the borrower's loan get recalled by the lender, it is the borrowers' responsibility to return shares to the lender either by buying shares in the market or by borrowing the shares from another lender. If the borrower fails to return the shares, the lender can use the borrower's collateral to buy shares to cover the loan, a procedure known as a buy-in. When a stock become hard to borrow, the borrower can not promptly find a lender willing to lend the shares and he or she is more prone to be bought-in by the firm in charge of the loan which needs to deliver shares to the lender according to the existing settlement agreement. Other things being equal, an unexpected buy-in event may suddenly increase the demand far beyond the existing supply and cause a jump in the asset prices.

In turn, short selling is a controversial topic both in the academic literature and in the financial markets regulation. According to the US Securities Exchange

\footnotetext{
${ }^{1}$ NASD rule 3370, https://www.sec.gov/rules/sro/34-49285.htm

${ }^{2}$ If the lender is a pension fund, there is an explicit requirement established by force of the Employee Retirement Income Security Act (ERISA) of 1974. In case of mutual funds, recall rights are required under the Investment Company Act of 1940.
} 
Commission (SEC), short-selling is defined ${ }^{3}$ as "the sale of a security that the seller does not own or that the seller owns but does not deliver. In order to deliver the security to the purchaser, the short seller will borrow the security."

Regulators have often alleged that a practice of short selling magnifies the decline of asset prices, it has been banned and restricted many times through history. To cite some notorious instances: the Dutch Tulip-mania in the seventeenth century, the U.S. stock price crash in 1929, the NASDAQ price bubble of 1998-2000 and more recently the housing price bubble and the credit crunch of 2008. The most recent example was in September of 2008 with the prohibition of short-selling by the SEC for 799 financial companies in an effort to stabilize the selling pressure for those companies. At the same time the U.K. Financial Services Authority (FSA) prohibited short selling for 32 financial companies. In September of the same year, Australia enacted even more extensive measures with a total ban of short selling (ASIC, 2008).

Since Diamond and Verrecchia (1987) an extensive list of papers have tried to measure empirically the impact of short-sale constraints on asset prices. According to theory, the level of short-selling can predict short-run future returns through two channels. One channel relates to the demand-side of the stock lending market: short-sellers are informed. The other channel relates to the supply-side: short-sellers are restricted. Measuring the importance of each channel is empirically challenging when, in general, supply and demand in the stock lending market are not directly observable.

Over the last 30 years, an extensive literature has been produced on this topic. Among others, ${ }^{4}$ Lamont (2004) discusses evidences that supports the overpricing hypothesis by using data from three episodes: short selling in 1920s and 1930s, Palm/3Com in the year 2000 and the tech stock mania of 1998-2000. Evidence that short-sellers take positions in firms with price declines is provided by Lamont (2004) who find that aggregate short-interest for NASDAQ-listed companies is positively associated with prior month declines in the NASDAQ index. Chague, De-Losso, De Genaro, and Giovannetti (2014) performed a comprehensive analysis on the Brazilian market and found evidence in favor of both the information hypothesis and the overpricing hypothesis. According to their findings, short sellers are informed traders, however, because short sellers

\footnotetext{
3 This definition can be found on the SEC website, http://www.sec.gov/rules/concept/34-42037 htm

4 To cite only the most recent papers: Saffi and Sigurdsson (2011), Boehmer and Wu (2013).
} 
are usually unable to sell short as much as they are willing to, prices do not reflect all information present in the market.

It is important to note that the critics of short-selling strategies may have a partial understanding on how this strategy works on practice. As pointed out by Abreu and Brunnermeier (2002), to implement a short selling strategy the investor is taking risks and is also subject to holding costs. For example, several explicit costs arise when an stock is sold short. First, short-sellers must hold the short-sale proceeds in a margin account that pays minimal interest. Moreover, if the stock is "on special" (or hard to borrow) that is, if it is difficult to locate shareholders who are willing to lend the share, short-sellers will receive a negative interest rate on their short-sale proceeds. In other words, the short-seller is indirectly paying a lending fee. Second, margin requirements force short-sellers to put additional money into low interest bearing margin accounts. Finally, a latent risk arises for loans without a guaranteed term, because under a recall notice the short seller might need to cover the short position in a rising market. Moreover, short positions in hard-to-borrow stocks may be forcibly bought in by the broker. Therefore, the short-selling strategy does not provide a risk free profit for the investor, as matter of fact, the short-seller carry many risks and their profit or loss is affected by whether and when their short stock is bought back in and at what price.

As pointed above, a hard-to-borrow stock is essentially a security that presents an increased likelihood of buy-ins. In turn, the buy-in events may potentially introduce discontinuous movements in the asset prices as result of a sharp increase in its demand by short-seller seeking to cover a short position. In this sense, the occurrence of jumps are no longer unobservable, but could be identified with buy-in events. However buy-ins historical data are not available so our identification strategy will focus on an observable variable, the lending rate.

The literature on jumps has many papers where point process intensity is modeled as a function of state variables, among others, we can cite Johannes, Kumar, and Polson (1999) which specify the probability of a jump arrival as a function of a set of state variables, which includes, for instance, lagged jumps or market variables. Another formulation proposed to link jumps to observable variables is the paper by Piazzesi (2005), where jumps intensities depend on the state of the economy and the meeting calendar of the Federal Open Market Committee. Recently De De Genaro and Avellaneda (2018) proposed 
the adoption of a deterministic point process to describe jumps around central bank meetings and obtained a closed-form solution for pricing overnight interest rate derivatives.

Differently from aforementioned works, in the present paper we do not focus either to measure whether and how short-selling constraint impacts asset prices, or whether short-seller can predict better future stocks performance. Here we want to investigate whether spikes in lending rate, acting as a proxy for buy-in events of hard-to-borrow stocks, can impact asset prices. To achieve our go we implement the model of Avellaneda and Lipkin (2009) extended to incorporate an affine intensity to drive the point process and so make the model tractable for estimation.

In line with Avellaneda and Lipkin (2009) we formulate a model to describe the price evolution of a stock and through a no-arbitrage argument we identify the lending rate as the intensity driving the point process which impacts stock prices. Once the theoretical model is set up we turn to check empirically whether the lending rate for hard to borrow stocks impacts its price for a selected group of Leveraged ETFs (LETF) prices. The model is estimated using an extended version of the method of simulated maximum likelihood (SML) developed by Pedersen (1995) and Brandt and Santa-Clara (2002), modified here as in Piazzesi (2005) to include jumps.

The rest of this paper is organized as follows. Section 2 presents an overview of how securities lending transactions are carried. Then, Section 3 presents the theoretical model to describe the asset prices under buy in effects. Section 4 describes the model's estimation and its computational aspects. In section 5 we present our estimation results. Finally, section 6 presents our concluding remarks.

\section{The securities lending market}

Since late 80's different international entities such as BIS and G30 have recommended the development of securities lending programs as means to increase efficiency and reduce the risk linked to securities settlement. According to the G30's recommendation, ${ }^{5}$ "competent authorities should allow equities to borrowed and lent as loans, in such a way to maximize the settlement of transaction with securities". A more in-depth description of securities lending markets

${ }^{5}$ G30, Recommendation 7 (G30, 2003, pp.85-87). 
might be found in Evans, Geczy, Musto, and Reed (2009), Duffie, Gârleanuc, and Pedersen (2002), and D'Avolio (2002). Securities lending services evolved significantly in the last years increasing market liquidity thus benefiting investors with both short and long strategies.

In a stock loan transaction, the security is transferred to the borrower, who undertakes to return all dividends to the lender together with the securities. The borrower is required to pledge collateral as a way to guarantee that their obligations will be met. Collateral is almost always cash, and the standard collateral for U.S. equities is $102 \%$ of the shares value and $105 \%$ for international securities. At the loan origination the parties negotiate the lending rate and rebate rate, which is the amount of interest on the collateral that the lender will rebate to the borrower. Under SEC Regulation T, shorting retail customers of brokers must, in addition to the cash collateral, post $50 \%$ of the market value of the stock in additional collateral, although this additional collateral may be posted in Treasury Bills. The equity-borrower therefore is also a lender of cash, and the rebate rate is his interest on this loan. The rebate rate is determined by supply and demand in the market for borrowing stocks and effectively determines the price of a stock loan. In the fixed income market, in particular with repo transactions, there is the General Collateral financing concept, or GC, which are a type of repurchase agreement that is executed without the designation of specific securities as collateral until the end of the trading day. The same terminology and measurement applies in the equity market, except that the interest rates in Repos correspond to rebate rates in equity loans. The majority of loans in the equity lending market are made in widely held stocks that are cheap to borrow. However on less widely held stocks or securities with large borrowing demand (hard to borrow) rebates may be reduced, in which cases, the stock are said to be trading special or just special.

As mentioned before, most loans are on a continuing basis, meaning they are subject to renegotiation and to termination by either party every day. Term loans, which are not open to renegotiation until a specific future date, are also available but less common. Given notice of recall, the borrower has a predetermined number of days ${ }^{6}$ to return the shares. In this case the borrower can try borrowing other shares from another lender, or otherwise cover the short

\footnotetext{
6 The number of days vary according to the market. In the US exchange Act Rule 15c3-3(d)(1) requires that the securities loaned must be returned within five business days following the recall notice. In Brazil, in case the lenders recall the securities, the borrower has until $T+4$ to provide the securities.
} 
position by purchasing the shares in the open market. If the borrower fail to return the stocks within this period, the lender has the legal right to use posted collateral to buy in, that is, must buy the stock outright. With a buy-in, the short sale is effectively interrupted. A theoretical model to incorporate the buy-in effects over the asset prices was developed by Avellaneda and Lipkin (2009).

Finally, securities lending is not limited to strategies that allow investors to profit from a price decline or to obtain securities to deliver under a prior lending agreement, stocks may also be borrowed in order to gain access to voting rights or to hedge a trading strategy, such as options market-maker. Options market makers, for example, hedge long options positions by shorting the underlying stock. While most stock market maker positions are closed out at the end of each day, options market makers take short positions that last until an option contract expires, which may be weeks or months in the future. Therefore, stocks that become hard to borrow impose an additional source of risk for options market makers because he may be subject to frequent buy-ins on their short position.

\section{The theoretical model for hard to borrow stocks}

In order to introduce the financial framework we will work with, we consider a filtered probability space $\left(\Omega, \mathcal{G},\left\{\mathcal{G}_{t}\right\}_{t \geq 0}, \mathbb{P}\right)$, where $\Omega$ is the set of all the possible events, $\left\{\mathcal{G}_{t}\right\}_{t \geq 0}$ is filtration, and $\mathbb{P}$ represents the so-called objective (real-world) measure.

Avellaneda and Lipkin (2009) propose a model to describe the price-evolution of stocks that are subject to restrictions on short-selling, generically referred to as hard-to-borrow. The model consists of a coupled system of stochastic differential equations (SDE) describing the stock price, $S_{t}$ and the "buy-in rate", $\lambda_{t}$, an additional factor absent in standard models. Here, we extend Avellaneda and Lipkin (2009) model to make it tractable for estimation.

To properly model stochastic timed events, we assume that there is a counting process $\left(N_{t}\right)_{t \in \mathbb{R}_{+}}$, counting the number of events that occur up to time $t$ and define $\tau_{j}$ for the time of the $j$ th event of interest after a starting time:

$$
N_{t}=\sum_{j} \mathbb{1}_{\left\{\tau_{j} \leq t\right\}}
$$


where $\left(\tau_{j}\right)_{j \geq 1}$ are inaccessible stopping times as defined in Bremaud (1981).

Let $\left(Y_{j}\right)_{j \geq 1}$ denote a iid sequence of random variable with probability distribution $\nu(d y)$ on $\mathbb{R}$, independent of the point process $\left(N_{t}\right)_{t \in \mathbb{R}_{+}}$, then $J_{t}$ defines a compound point process:

$$
J_{t}=\sum_{j=1}^{N_{t}} Y_{j}
$$

Given that $N_{T}=n$, the $n$ jump sizes of $\left(J_{t}\right)_{t \in \mathbb{R}_{+}}$on $[0, T]$ are independent random variables which are distributed on $\mathbb{R}$ according to $\nu(d y)$. Additionally, if we assume: (i) $N_{0}=0$; (ii) $N_{t}$ has independent increments; and (iii) $N_{t}-N_{s}$ is a Poisson random variable with a given intensity $\lambda_{t}$, then $\left(N_{t}\right)_{t \in \mathbb{R}_{+}}$is called a Poisson point process. By construction, compound Poisson processes only have a finite number of jumps on any finite interval.

While the Wiener process is itself a martingale, a Poisson process as such is not. It becomes a martingale if one subtracts from $N_{t}$ the process given by its mean. Indeed,

$$
M_{t}=N_{t}-\int_{0}^{t} \lambda_{t} \mathrm{~d} t
$$

is an $\mathcal{G}_{t}$-martingale by the $\mathcal{G}_{0}$-measurability of $\lambda_{t}$ and by assuming in addition that $\lambda_{t}$ is integrable.

Under the objective measure, $\mathbb{P}$, the price-evolution of stock satisfies the SDE:

$$
\frac{\mathrm{d} S_{t}}{S_{t^{-}}}=\mu \mathrm{d} t+\sigma \mathrm{d} W_{t}+\mathrm{d} J_{t}
$$

where $S_{t^{-}}=\lim _{s \uparrow t} S_{s}$ and processes $\left(W_{t}\right)_{t \geq 0}$ and $\left(J_{t}\right)_{t \geq 0}$ are, respectively, a standard Brownian motion and a compound Poisson process with intensity $\lambda_{t}$ under the measure $\mathbb{P}$.

The number of jumps, $N_{t}, t \geq 0$, is described by the doubly stochastic Poisson process (DSPP) with intensity $\lambda_{t}$, satisfying the following property: for all $T>0$, points $0=t_{0}<t_{1}<\cdots<t_{l}=T$ and values $k_{1}, \ldots, k_{l}$ in $\{0,1, \ldots$,$\} ,$

$$
\mathbb{P}\left(N_{t_{j}}-N_{t_{j-1}}=k_{j}, 1 \geq j \geq K\right)=\mathrm{E}\left[e^{-\Lambda_{0, t}} \prod_{j=1}^{l} \frac{1}{k_{j} !} \Lambda_{t_{j-1}, t_{j}}^{k_{j}}\right]
$$


where

$$
\Lambda_{t, t^{\prime}}=\int_{t}^{t^{\prime}} \lambda_{u} \mathrm{~d} u, \quad \text { for } 0 \leq t<t^{\prime} .
$$

Here $\lambda_{t}, t \geq 0$, is the stochastic jump's intensity.

In what follows, we also assume that the intensity $\lambda_{t}$ is driven by an onedimensional Feller (a.k.a. CIR) process, that is, that $\lambda_{t}$ is a random process with non-negative values and solves

$$
\mathrm{d} \lambda_{t}=\kappa\left(\theta-\lambda_{t}\right) \mathrm{d} t+\sigma_{2} \sqrt{\lambda_{t}} \mathrm{~d} W_{t}
$$

Under the model's assumptions, asset prices are subjected to jumps. The inclusion of jumps gives rise to an incomplete market model in a sense that we have a family of measures, $\mathcal{M}, \mathbb{Q}$ equivalent to $\mathbb{P}$.

In order to characterize the elements of $\mathcal{M}$, the set all absolutely continuous measures $\mathbb{Q} \sim \mathbb{P}$, we make use of the two versions of Girsanov's Theorem, ${ }^{7}$ where one is for changes in the Brownian motion and one for changes in a nonexplosive counting process with intensity $\lambda_{t}$. Under the Girsanov's Theorem we may state that the Radon-Nikodým derivative is given by

$$
\frac{\mathrm{d} \mathbb{Q}}{\mathrm{dP}}=\exp \left\{\int_{0}^{t}\left[\left(1-\Psi_{s}\right) \lambda_{s}-\frac{1}{2} \Upsilon_{s}^{2}\right] \mathrm{d} t+\int_{0}^{t} \Upsilon_{s} \mathrm{~d} W_{s}+\int_{0}^{t} \log \Psi_{s} \mathrm{~d} N_{s}\right\} .
$$

Measure changes for jump processes are more flexible than those for diffusions. Girsanov's theorem only requires that the intensity be predictable and that the jump distributions have common support. With constant intensities and state-independent jump distributions, the only constraint is that the jump distributions be mutually absolutely continuous (see Theorem 33.1 in Sato, 1999 and Corollary 1 of Cont \& Tankov, 2003). Assuming that Novikov's condition is satisfied for $\Upsilon_{t}$ and that $\lambda_{t}$ is $L^{1}(\Omega)$, we can state:

$$
\begin{aligned}
& \mathrm{d} W_{t}^{Q}=\mathrm{d} W_{t}-\Upsilon_{t} \mathrm{~d} t \\
& \mathrm{~d} M_{t}^{Q}=\mathrm{d} N_{t}-\Psi_{t} \lambda_{t} \mathrm{~d} t
\end{aligned}
$$

Thus, the Radon-Nikodým derivative for an absolutely continuous change of measure from $\mathbb{P}$ to $\mathbb{Q}$, implies a translation of the Wiener by $\Upsilon_{t}$ and a change of the Poisson intensity from $\lambda_{t}$ to $\Psi_{t} \lambda_{t}$. Therefore with the help of equation (3)

${ }^{7}$ Details can be found in Bremaud (1981). 
the dynamics of $S_{t}$ under $\mathbb{Q}$ become

$$
\frac{\mathrm{d} S_{t}}{S_{t^{-}}}=\left(\mu+\Upsilon_{t} \sigma_{t}+\Psi_{t} \lambda_{t}\right) \mathrm{d} t+\sigma \mathrm{d} W_{t}^{Q}+\mathrm{d} M_{t}^{Q}
$$

As pointed above, the equity-borrower is also a lender of cash, so the risk free rate, $r_{t}^{\text {rf }}$, is his interest on this loan and simultaneously he has to pay borrow-rate, $r_{t}^{\mathrm{L}}$. Thus his money account evolves as $\mathrm{d} B_{t}=\left(r_{t}^{\mathrm{rf}}-r_{t}^{\mathrm{L}}\right) B_{t} \mathrm{~d} t$. So our strategy to choose one element from $\mathcal{M}$ is to define $B_{t}$ as numeraire. Thus we immediately see that if $\Upsilon_{t}$ and $\Psi_{t}$ are chosen such that $\mu+\Upsilon_{t} \sigma_{t}+\Psi_{t} \lambda_{t}=r_{t}^{\mathrm{rf}}-r_{t}^{\mathrm{L}}$ then we obtain a $\mathbb{Q}$ martingale measure for the discounted price $B_{t}^{-1} S_{t}$. When the underlying variable is a traded asset, the Black and Scholes (1973) argument eliminates the need for the market price of risk and among many forms for $\Psi_{t}$ we choose:

$$
\begin{aligned}
& \Upsilon_{t}=\sigma^{-1}\left(r_{t}^{\mathrm{rf}}-\mu\right), \\
& \Psi_{t}=\frac{r_{t}^{\mathrm{L}}}{\lambda_{t}} .
\end{aligned}
$$

For interpretation purposes, we refer to $\Upsilon_{t}$ and $\Psi_{t}$ as risk premia. Concerning the market price of risk, $\Upsilon_{t}$, we have a standard definition, whereas $\Psi_{t}$ is the market price of jump-risk. With these constraints we can show that the discounted stock price $B_{t}^{-1} S_{t}$ is a $\mathbb{Q}$-martingale.

From equation (11) we make explicit the relation between the jump intensity and the lending rate, which is very useful for model's estimation and identification, since the intensity $\lambda_{t}$ is no longer a latent variable. Even though we have introduced a martingale measure, our estimation strategy will only rely on time-series returns rather than cross-section of options prices. There is a large literature on the use of joint data on the underlying asset and option prices for the joint estimation of the model, among others, we cite Bollen (1997), Eraker (2004), and Broadie, Chernov, and Johannes (2007).

It is important to note that the absolute continuity requirement implies that certain model parameters, or combinations of parameters, are the same under $\mathbb{P}$ and $\mathbb{Q}$ measures. This is a mild but important economic restriction on the parameters. This implies that these parameters can be estimated using either equity price returns or option prices, but that the estimates should be the same from either data source. In our model, we have followed a identification strategy where the intensity is no longer a latent variable thus all the parameters are the 
same under both measures, but this equality may not be valid when a different form to characterize the market price of jump risk is assumed. One way to impose this theoretical restriction is to constrain these parameters to be equal under both measures, it is the time-series consistency as advocated by Broadie et al. (2007).

\section{Model Estimation}

In this section we present the simulated maximum likelihood (SML) method introduced by Pedersen (1995) and Brandt and Santa-Clara (2002) which is implemented to estimate the parameters of our model. An equivalent implementation of SML with jumps was performed in Piazzesi (2005). The SML allows the estimation of a wide variety of diffusion processes, including those which lack of closed-form expressions for the transition density. The main idea underlying SML is to numerically evaluate the transition probabilities of the process corresponding to all pairs of values taken by the state variable at consecutive times. If a discretization of the time space axes is properly refined, the resulting transition density approaches a Gaussian distribution. The likelihood estimator becomes a reliable approximation of the exact maximum likelihood estimator, namely the one stemming from the exact, yet unknown, transition density of the process.

We consider the problem of estimating the parameters of a continuous-time jump-diffusion process $S_{t}$ satisfying a stochastic differential equation (SDE):

$$
\mathrm{d} S_{t}=\mu\left(S_{t}, t\right) \mathrm{d} t+\sigma\left(S_{t}, t\right) \mathrm{d} W_{t}+\mathrm{d} J_{t},
$$

where $\mu(\cdot)$ is the drift, and $\sigma(\cdot)$ is the diffusion coefficient. Here $J_{t}$ is a compound jump process as defined in equation (2).

We assume that (12) has a nonexploding, unique solution. Explosive solutions are excluded because in their case no transition density exists. Among the various alternative sets of sufficient conditions ensuring that this assumption actually holds, the simplest one is that $\mu\left(S_{t}, t\right)$ and $\sigma\left(S_{t}, t\right)$ satisfy global Lipschitz and linear growth conditions. ${ }^{8}$

In this setting, the probability of no jump, $\mathbb{P}\left(N_{t_{i+1}}-N_{t_{i}}=0 \mid \lambda_{t_{i}}\right)$, between $t_{i}$ and $t_{i+1}=t_{i}+\delta$, is given according to De De Genaro and Simonis (2015)

\footnotetext{
${ }^{8}$ Karatzas and Shreve (1991) and Aït-Sahalia (2002) discuss alternative sets of sufficient conditions which can be better suited to deal with SDEs which do not meet the previous requirements and are frequently encountered in finance.
} 
who derived a closed-form solution for the probabilities of the corresponding DSPP, $N_{t}$ by exploring the affine structure of $\lambda_{t}$ stated by (7):

$$
\mathbb{P}\left(N_{t_{i}+\delta}-N_{t_{i}}=0 \mid \lambda_{t_{i}}\right)=\exp \left(\alpha(\delta)+\beta(\delta) \lambda_{t_{i}}\right)
$$

where

$$
\alpha(\delta)=\frac{2 \kappa \theta}{\sigma_{2}^{2}} \ln \left(\frac{2 \zeta\left(e^{(\zeta+\kappa) / 2}\right)}{(\zeta+\kappa)\left(e^{-\zeta \delta}-1\right)+2 \zeta}\right)
$$

and

$$
\beta(\delta)=\left[\frac{2\left(e^{-\zeta \delta}-1\right)}{(\zeta+\kappa)\left(e^{-\zeta \delta}-1\right)+2 \zeta}\right]
$$

with

$$
\zeta=\sqrt{\kappa^{2}+2 \sigma_{2}^{2}}
$$

We assume, as in Merton (1976), that jump sizes are Gaussian distributed with mean $\mu_{Y}$ and variance $\sigma_{Y}^{2}$, in which case $\nu(d y)=\phi_{\mathcal{N}}\left(\mu_{Y}, \sigma_{Y}^{2}\right)$. Essentially, this component adds mass to the tails of the returns distribution. Increasing $\sigma_{Y}$ adds tail mass to both tails while a negative (say) $\mu_{Y}$ implies relatively less mass in the right tail, and vice versa. A far more general formulation to describe jumps is by means of a Generalized Hyperbolic distribution introduced in finance by Eberlein and Keller (1995). An important aspect is that Generalized Hyperbolic distributions is a five-parameters family and embrace many special cases as its limiting distributions, for instance the normal inverse Gaussian (NIG), Student-t, Variance-Gamma (VG) and Normal distributions.

Given the possibility of nesting various models with the Generalized Hyperbolic distributions it is tempting to estimate parameters for this hyper-family. The point is that by increasing the dimension of parameter space the maximization problem becomes less tractable. As pointed by Prause (1999) the likelihood function presents relevant flat regions over the parametric space, consequently using the Generalized Hyperbolic family leads to imprecise parameter estimates, unless some ad hoc parametric restrictions are made, which amounts to choosing a subfamily of models. This aspect orientated our decision toward choosing the Normal distribution for describing the jumps size.

\subsection{Estimation framework}

The vector $\mathbf{S}=\left(S_{0}, S_{1}, \ldots, S_{N}\right)$ gathers a set of observations of the process as recorded at consecutive times $t_{0}, \ldots, t_{N}$. If the exact transition density function 
$p_{S}=p_{S}\left(S_{t+1}, t+1, S_{t}, t ; \boldsymbol{\theta}\right)$ is available in analytic form for any pair of times $t<t+1$ and states $S_{t+1}, S_{t}$, the likelihood function of the process is defined as the joint density computed at the observed value $\mathbf{S}$, i.e.,

$$
\mathcal{L}(\boldsymbol{\theta} ; \mathbf{S})=\prod_{n=0}^{N-1} p_{S}\left(S_{n+1}, t_{n+1}, S_{n}, t_{n} ; \boldsymbol{\theta}\right)
$$

The parameter vector is $\boldsymbol{\theta}=\left(\mu_{Y}, \sigma_{Y}, \mu, \sigma, \kappa, \theta, \sigma_{2}\right)^{\prime} ; \boldsymbol{\theta}$ is an unknown parameter in a bounded set $\Theta \subseteq \mathbb{R}^{7}$. Here $\mu_{Y}$ and $\sigma_{Y}$ are, respectively, the average size and standard deviation of jumps, $\sigma$ is the volatility and $\mu$ the drift of the Brownian motion process, $\kappa, \theta$, and $\sigma_{2}$ are respectively the speed of mean reversion, the long term average and the volatility of the intensity process. Note that classical compound Poisson process is obtained when $\sigma_{2}=0$ and $\lambda_{0}=\theta$, then $\lambda_{t}=\theta$ at all $t$.

The maximum likelihood estimator determines the parameter value maximizing the likelihood function computed on a sample $\mathbf{S}$. The theory of stochastic processes estimation using maximum likelihood is largely developed (see, e.g., Prakasa Rao, 1999). However, the method requires an analytical expression for the transition densities of the process, $p_{S}$. When the transition density $p_{S}$ does not exist in closed-form thus it must be approximated. The Simulated Maximum Likelihood (SML) method, developed independently by Pedersen (1995) and Brandt and Santa-Clara (2002), approximates transition function values using Monte Carlo simulation. This technique provides an answer whenever other approximating methods fail. On the other hand, it suffers from all the typical inconveniences of simulation-based techniques such as intensive time consuming. In order to reduce the computational time, we estimate the model using parallel computing. Parallel computing is suitable to solve problems involving Monte Carlo simulation, because each repetition can be assigned to a different calculation's core. As SML is basically a Monte Carlo with different layers we were able to speed up our results 20 times when compared to a serial estimation. ${ }^{9}$

The SML provides an approximation for the transition function

$$
p_{S}\left(S_{t+1}, t+1, S_{t}, t ; \boldsymbol{\theta}\right)
$$

between consecutive times $t_{n}$ and $t_{n+1}$. For the sake of simplicity, we assume

\footnotetext{
${ }^{9}$ More details about the parallel computing implemented in this paper are available upon request.
} 
that sampling occurs on an evenly $\Delta$ spaced time grid $t_{0}, \ldots, t_{N}$. Each interval $\left[t_{n}, t_{n+1}\right]$ is first split into $M$ subintervals of length $\delta=\frac{\Delta}{M}$. Next, the transition is rewrite using the Chapman-Kolmogorov equation as the convolution of densities over two consecutive intervals $\left[t_{n}, t_{n+1}-\delta\right]$ and $\left[t_{n}-\delta, t_{n+1}\right]$ :

$$
\begin{aligned}
p_{S}\left(S_{n+1}, t_{n+1},\right. & \left.S_{n}, t_{n} ; \boldsymbol{\theta}\right) \\
& =\int_{\mathbb{R}} p\left(S_{n+1}, t_{n+1}, S_{n}, t_{n}-\delta ; \boldsymbol{\theta}\right) p\left(s, t_{n+1}-\delta, S_{n}, t_{n} ; \boldsymbol{\theta}\right) \mathrm{d} \mathbf{s}
\end{aligned}
$$

This expression can be interpreted as the expected value of the transition probability $p\left(S_{n+1}, t_{n+1}, S_{n}, t_{n}-\delta ; \boldsymbol{\theta}\right)$ as a function of $s$, with respect to the distribution of the process $\mathbf{S}$ at time $\left[t_{n}, t_{n+1}-\delta\right]$ :

$$
p_{S}\left(S_{n+1}, t_{n+1}, S_{n}, t_{n} ; \boldsymbol{\theta}\right)=\mathbb{E}_{t_{n}, S_{n}}\left[p\left(S_{n+1}, t_{n+1}, S\left(t_{n+1}-\delta\right), t_{n+1}-\delta ; \boldsymbol{\theta}\right)\right] .
$$

To compute this expectation, we need information about two quantities: (i) an expression for $p$; and (ii) the distribution of process $\mathbf{S}$ at time $\left[t_{n+1}-\delta\right]$ given $S\left(t_{n}\right)=S_{n}$. Within the SML framework, both quantities are computed using numerical approximations. To this aim, we implement the Euler-Maruyama (EM) approximation ${ }^{10}$ of $S_{t}$ by mean of a continuous stochastic process $S_{t_{n}}$ satisfying the iterative scheme over a refined time grid:

$$
\begin{aligned}
S_{t_{n}+(m+1) \delta}^{M}=S_{t_{n}+m \delta}^{M}+\mu S_{t_{n}+m \delta}^{M} \delta+\sigma & S_{t_{n}+m \delta}^{M} \sqrt{\delta} \times \epsilon_{n, m}^{1} \\
& +\mathbb{1}_{\left\{t_{n}+m \delta\right\}}\left(\mu_{Y}+\sigma_{Y}^{2} \times \epsilon_{n, m}^{2}\right),
\end{aligned}
$$

where $\epsilon_{n, m}^{i}$ for $i=12$ are independent standard Gaussian variables defined for all discretization indices $(n=0, \ldots, N-1)$ and all refining indices $(m=0, \ldots, M-1)$. The convergence of numerical schemes for SDEs needs conditions on the drift and diffusion coefficients. These conditions are namely linear growth and global Lipschitz conditions. ${ }^{11}$

Kloeden and Platen (1999) show that as the accuracy of the Euler-Maruyama

10 The literature on numerical methods for stochastic differential equations provides more efficient discretization schemes that Euler-Maruyama, such as the Milstein and Platen-Wagner schemes but here we follow Brandt and Santa-Clara closely. Elerian (1998) and Durham and Gallant (2002) show that the SML estimator can be generalized to any discretization with closed-form transitions, including the Milstein scheme.

${ }^{11}$ We note that Yamada (1978) relaxed the global Lipschitz condition, whilst Kaneko and Nakao (1988) have shown that the Euler scheme converges in the strong sense, to the solution of the stochastic deferential equation whenever path-wise uniqueness of the solution holds. 
discretization increases, or formally as $M \rightarrow \infty$ and thereby $\delta \rightarrow 0$, the transition density of the EM discretization weakly converges to the corresponding transition density of the continuous-time process. Kloeden and Platen (1999) also show that with constant diffusion coefficients, Euler-Maruyama and Milstein method coincide, so are of the same order of convergence.

The jump occurrence is described by the indicator function

$$
\mathbb{1}_{\left\{t_{n}+m \delta\right\}}= \begin{cases}1, & \text { if } t_{n}+m \delta \text { is a jump time } \\ 0, & \text { otherwise }\end{cases}
$$

Furthermore to simulate the jumps, we use the fact that the jump time distribution can be computed in a closed-form. Initially consider the point process $N_{t}=\mathbb{1}_{\{\tau<t\}}$ with the intensity following the mean reverting square root process as defined by equation (7) which starts at $\lambda_{0}>0$. In addition, provided that $\kappa$, $\theta>0$, and $2 \kappa \theta>\sigma^{2}$, the process stays always positive during the entire lifetime. Then, $\mathbb{P}(\tau<t)=1-\mathbb{E}\left[\exp \left(-\int_{0}^{t} \lambda_{u} \mathrm{~d} u\right)\right]$ and, in the case above, this quantity can be calculated analytically by equation (13). This computation, coupled with the inverse transformation method, leads to an exact algorithm for simulating jump time.

To obtain an approximation to $p$, one could use the asymptotic expansion method of Aït-Sahalia (2002, 2008) or Li (2013). However we have adopted a more simple approach by means of the Euler transition density, which is valid over short time intervals. Therefore, the first approximation involves the expectation in expression (19), which is calculated by running a Monte Carlo simulation of the discrete time process $S^{M}$ via equation (20). The estimate resulting from $K$ sample paths is as follows:

$$
p_{S}(\boldsymbol{\theta}) \simeq \frac{1}{K} \sum_{i=1}^{K} p\left(S_{t_{n+1}} t_{n+1}, S_{i, t_{n+1}-\delta}^{M}, t_{n+1}-\delta ; \boldsymbol{\theta}\right)
$$

Therefore, $p$ is the transition density of the discretized process on the interval $\left[t_{n+1}-\delta, t_{n+1}\right]$ and $S_{i, t_{n+1}-\delta}^{M}$ describes the realizations of the process $S^{M}$ drawn over the same time interval. Next, since $\delta$ in (20) is small in comparison to $\Delta$, we approximate the transition function, $p$ in (21) by the transition of the discrete process $(20)$ on the time interval $\left[t_{n+1}-\delta, t_{n+1}\right]$.

Moreover, jump sizes are normally distributed so the transition density of the discrete process between $t_{i}$ and $t_{i+1}$ is a mixture of Normal distributions. Finally, 
we assume that no more than one jump can occur on each interval of length $\delta$ in the refinement of the time axis, so $p_{0}^{(i)}=\mathbb{P}\left(N_{t_{n+1}}-N_{t_{n+1}-\delta}=0 \mid \lambda_{t}\right)$ is the probability of no jump over the interval $\left[t_{n+1}-\delta, t_{n+1}\right]$ which is calculated by equation (13). Therefore, the transition density $p$ can be expressed as a mixture of two Gaussian random variables weighted by the probability of zero or one jump in $\delta$ :

$$
\begin{aligned}
p\left(S_{t_{n+1}} t_{n+1}, S_{i, t_{n+1}-\delta}^{M}, t_{n+1}-\delta ; \boldsymbol{\theta}\right) & \\
= & p_{0}^{(i)} \phi_{\mathcal{N}}\left((1+\mu) \delta S_{i, t_{n+1}-\delta}^{M}, \sigma^{2} \delta S_{i, t_{n+1}-\delta}^{M}\right) \\
& +\left(1-p_{0}^{(i)}\right) \phi_{\mathcal{N}}\left((1+\mu) \delta S_{i, t_{n+1}-\delta}^{M}+\mu_{Y}, \sigma^{2} S_{i, t_{n}-\delta}^{M} \delta+\sigma_{Y}^{2}\right),
\end{aligned}
$$

where $\phi_{\mathcal{N}}$ is the Gaussian density.

As noted, the transition density (22) is a mixture of Normal densities and Kiefer (1978) has shown that for this type of distribution the global maximum for the log-likelihood function (17) does not exist. This is because a singularity arises when $S_{n}$ is exactly equal to $\mu$ for any $n$ then as $\sigma \rightarrow 0$ the equation (22) increases without bound. However, it is still possible to obtain a reliable estimates under mild assumptions, Hamilton (1994) and Kiefer (1978) have offered remedies to deal with the singularity problem associated with the mixture density. Here, we follow Kiefer (1978) by assuming that the parameter space is compact and large enough to include the true parameters.

Once we have computed the previous steps for all observations $n$, the likelihood function can be evaluated by formula (17), where we replace $p_{S}$ by jointly using (21) and (22). This strategy gives rise to a consistent approximation of the likelihood function $\mathcal{L}(\boldsymbol{\theta} ; \mathbf{S})$. Pedersen (1995) and Brandt and Santa-Clara (2002) prove that under the usual regularity conditions if $M \rightarrow \infty$, and $K \rightarrow \infty$, with $K^{1 / 2} / M \rightarrow 0$ then both the SML estimator and the maximum likelihood estimator share common asymptotic properties.

\subsection{Computational aspects}

Although the simulation-based approach has great intuitive appeal, it can be computationally burdensome. In general most of the standard algorithms to optimize $^{12} \mathcal{L}(\boldsymbol{\theta} ; \mathbf{S})$ are quite sensitive to the initial condition $\boldsymbol{\theta}_{0}$ passed on $\mathcal{L}(\boldsymbol{\theta} ; \mathbf{S})$. To overcome the usual difficulties arising during the optimization procedure

\footnotetext{
${ }^{12}$ For instance, fminserach or fminunc in Matlab ${ }^{\circledR}$.
} 
we have implemented a two step estimation strategy. During the first step, we preprocess the optimization through a coarse grid global method to avoid getting trapped in a local minimum. We start the optimization, by running a Pattern Search (PS) optimization algorithm. ${ }^{13} \mathrm{PS}$ is an evolutionary technique that is suitable to solve a variety of optimization problems that lie outside the scope of the standard optimization methods. Generally, PS has the advantage of being very simple in concept, easy to implement and computationally efficient. Unlike other heuristic algorithms, such as genetic algorithms advocated by Michalewicz (1996), PS possesses a flexible and well-balanced operator to enhance and adapt the global and fine tune local search. A useful review of direct search methods for unconstrained optimization is presented in Lewis, Torczon, and Trosset (2000), where the authors give a modern perspective on the classical family of derivative-free algorithms, focusing on the development of direct search methods. $^{14}$

Once PS algorithm has converged to $\boldsymbol{\theta}_{1}$, we randomly choose a point $\boldsymbol{\theta}_{2}$ such that $\left\{\boldsymbol{\theta}_{2}:\left|\boldsymbol{\theta}_{1}-\boldsymbol{\theta}_{2}\right|<\Xi\right\}$ as starting point for the second step. For the second step we use ${ }^{15}$ the standard Descent Method to maximize $\mathcal{L}(\boldsymbol{\theta} ; \mathbf{S})$. In this method, the algorithm solves a quadratic programming (QP) subproblem at each iteration and updates an estimate of the Hessian of the Lagrangian at each iteration using the Broyden, Fletcher, Goldfarb, and Shanno (BFGS) algorithm.

Moreover, the SML method requires a intensive use of simulations, which must be controlled by suitable variance reduction techniques to reduce the number of computations as well as to enhance its performance. In practice, we use the method of antithetic variates, ${ }^{16}$ which has two properties: cut in half the number of normal samples to be taken to generate $N$ paths, and it reduces the variance of the sample paths, improving the accuracy.

Note also that the quality of the SML estimator depends on discretization steps $M$ and the simulation size $K$. Increasing $M, K$, or both, improves the approximation of the transition densities and thus results in an estimator that behaves more like the maximum likelihood estimator. However, at the same time, it increases the computational burden to evaluate the approximate likelihood

13 patternsearch is an implementation in Matlab ${ }^{\circledR}$ for this algorithm.

${ }^{14}$ A classic reference about nonlinear optimization in econometrics is Goldfeld and Quandt (1972).

${ }^{15}$ Implemented in Matlab ${ }^{\circledR}$ as fminunc function.

16 The use of antithetic variates and other variance reduction techniques can be found in Kloeden and Platen (1999). 
function. Although the computational power increases, it is necessary to find a reasonable trade-off between the increasing of $M$ and $K$ and the tractability of the model's estimation.

In this work we have followed Stramer and Yan (2007) and set $M=K^{2}$. While for setting $K$ we assume the value proposed by Brandt and Santa-Clara (2002), $K=5000$ (plus 5000 antithetic variates) to approximate the likelihood function. Furthermore, we have set $\Delta=10$ for the Euler discretization.

\subsection{A test of model fit}

Once jumps might occur independently of lending rates jumps, we confront our model with the pure jump-diffusion model of Merton (1976) where jumps occur according to a Poisson process with intensity $\lambda_{0}$ and with independent and normally distributed jumps. Under the alternative model, asset prices in presence of jumps are described by

$$
\mathrm{d} S_{t}=\mu S_{t} \mathrm{~d} t+\sigma S_{t} \mathrm{~d} W_{t}+\mathrm{d} J_{t}
$$

where $\mu(\cdot)$ is the drift, $\sigma(\cdot)$ the diffusion coefficient and $J_{t}$ is a compound jump process with constant intensity.

In the standard jump-diffusion model described in (23), the returns process consists of three components, a linear drift, a Brownian motion representing normal price variations and a compound Poisson process that accounts for abnormal price changes. By construction, compound Poisson processes only have a finite number of jumps on any interval. Nevertheless, as pointed by Cont and Tankov (2003), they belong to the family of Lévy processes which may have an infinite number of jumps on any finite time interval.

In principle, big jumps are changes in asset prices that are rare and much larger than what can be explainable by a diffusion process, these jumps can be detected by applying tests that look for large returns. On the other hand, recognizing jumps in discrete observations from continuous-time models becomes more difficult if the jump sizes are smaller, because they are of a size that could be in principle attributed to a diffusion process. In fact, the ability to disentangle jumps from volatility is the essence of risk management, which should focus on controlling large risks leaving aside the day-to-day Brownian fluctuations. Ait-Sahalia (2004) shows that likelihood-based statistical methods can be used to distinguish volatility from jumps, thereby the presence of jumps does not 
impact one's ability to estimate the diffusion parameter $\sigma$.

In spite of the widespread application of jump models, we also test whether jump-diffusions do have a better fit than the simpler diffusive case,

$$
\mathrm{d} S_{t}=\mu S_{t} \mathrm{~d} t+\sigma S_{t} \mathrm{~d} W_{t} .
$$

When comparing (23) and (24) with our model, given by equations, (4) and (7), we see that both models are nested and we obtain the pure jump-diffusion by imposing $\sigma_{2}=0$ and $\lambda_{0}=\theta$, then $\lambda_{t}=\theta$, for all $t$ in equation (7). Likewise we obtain the diffuse case when besides the former conditions we also impose $\lambda_{t}=\theta=0$ in equation (7).

Within the MLE and SML framework, the likelihood ratio test (LR) is the standard method for testing alternative hypothesis and under mild regularity conditions, the LR has an asymptotic $\chi^{2}$ distribution. However, statistical tests for jumps are particularly challenging for at least two reasons. First, these tests involve nuisance parameters, $\mu_{Y}$ and $\sigma_{Y}^{2}$, that are not identified under the no jumps null hypothesis, $H_{0}$. As it is well known since Self and Liang (1987) ${ }^{17}$ in the presence of nuisance parameters the tests limiting null distribution are not generally chi-square. Indeed, they can take a much more complex form, such as Andrews' (1993) sup $-\chi^{2}$ distribution or Hansen's (1996) $\chi^{2}$ processes. More importantly, as emphasized in Hansen (1996), in several situations, the relevant limiting distributions are nuisance dependent which preclude the construction of specialized critical point tables. One early approach to dealing with the problem is the asymptotic bounds procedure proposed in Davies $(1977,1987)$. Hansen (1996) and Andrews (2000) have proposed simulated-based procedure to approximate asymptotic $p$-values, which is valid in settings more general than Davies'

Second, the null hypothesis sets the parameter describing the arrival of jumps at a boundary of its permissible domain (the so-called "nesting-at-boundary" problem). As demonstrated by Andrews (2001), this situation produces difficulties similar to unidentification and standard asymptotics and even bootstraps may fail.

As pointed by Khalaf, Saphores, and Bilodeau (2003), all of the abovementioned statistical difficulties have important implications for the properties of

17 The same question was later addressed by Hansen (1996), Dufour (2006) and Andrews (2000, 2001). 
jump tests. In particular, spurious rejections, resulting from test size distortions, cannot be ruled out, which underscores the importance of accounting for sample size for inference. Indeed, Dufour (1997) and Andrews (2000, 2001) show that test size distortions are not a small sample problem, they occur because of the failure of standard asymptotics rather than slow convergence. Thus, spurious rejections may occur even with very large financial data sets. This precludes the application of standard simulation-based size correction techniques, such as specialized critical point tables or the standard bootstrap.

To overcome the limitations present in standard likelihood ratio tests, we implement the Monte Carlo test procedure proposed by Dufour and Khalaf (2001), which is highly related to the parametric boostrap procedure, see discussion in Dufour (1997). The methodology consists of combining boundedly pivotal statistics with the Monte Carlo test technique to tackle the difficulties plaguing available jump tests. First, it is established analytically that the LR no-jump test statistic is boundedly pivotal. Then, it is applied a simulation-based methods to the LR and to bounding statistics to obtain level-exact $p$-values in finite samples.

This approach has many advantages: (i) the MC $p$-value does not depend on $\mu_{Y}$ and $\sigma_{Y}^{2}$; (ii) the boundary restriction does not intervene here, since the only element of the proof concern the pivotal characteristic of the LR statistic; (iii) invariance to location and scale, i.e. $\mu\left(S_{t}\right)$ and $\sigma\left(S_{t}\right)$ in the case of equation (24); and (iv) the normality assumption is not necessary for the validity of the results. Furthermore this approach is also simple to implement and it is applicable to a large class of parametric models where unidentified nuisance parameters are present.

\section{Empirical Results}

In this section, we estimate our model with some real observed data and examine its goodness of fit. We choose to apply our model to some ETFs, particularly, Leveraged ETFs. A leveraged ETF tracks the value of an index, a basket of stocks, or another ETF with the additional feature that it uses leverage. The main reason to choose this kind of instruments is that managers of a bearish LETF may incur significant financing costs to maintain short positions if components of the underlying ETF or the ETF itself are hard-to-borrow.

According to Avellaneda and Lipkin (2009) predictions, we expect to confirm that changes in borrow rate affect the LETF prices. We also include a nonleveraged ETF which, in theory, should not be affected by hard to borrow effects. 
Our sample is formed by end-of-day data on 7 actively traded ETF's in the USA and their corresponding lending rates. ${ }^{18}$ We have a total of 513 observations for each pair (ETF, lending rate) covering the period from 26 June 2009 to 8 August 2011. Table 1 gives a list of ETF's analyzed in our study, their tickers, managing entity, leverage ratio, sector and corresponding asset under management (AUM).

Our sample is formed by 7 ETFs, composed by 6 leveraged (EDC, EDZ, UYG, SKF, FAS and FAZ) and one standard or unleveraged ETF (EEM). A leveraged ETF seeks a return that is $\pm X$ times the return of an index or other benchmark (target) for a single day. For instance, the ProShares Ultra Financial ETF (UYG) offers double exposure to the Dow Jones U.S. Financials index. To achieve this, the manager invests two dollars in a basket of stocks tracking the index per each dollar of UYG's net asset value (NAV), borrowing an additional dollar. Short LETFs, such as the ProShares UltraShort Financial ETF (SKF), offer a negative multiple of the return of the underlying ETF. In this case, the manager sells short a basket of stocks tracking the Dow Jones U.S. Financials index (or equivalent securities) to achieve a short exposure in the index of two dollars per each dollar of NAV. In both cases, the fund's holdings are rebalanced daily.

According to Avellaneda and Lipkin (2009), we expect that in presence of hard-to-borrow assets, the NAV for these ETF's be impacted, since ETF managers may face difficulties to borrow assets to achieve the targeted long and short exposures. Thus, we are interested in LETFs, in particular those that track financial indices, which have been often hard-to-borrow since July 2008. Moreover, as pointed by Avellaneda and Lipkin (2009) broad market ETFs such as SPY $^{19}$ have also been sporadically hard-to-borrow in the last quarter of 2008.

Observing Figure 1 we can see that for many ETFs the daily change in the lending rates are over 50\%. According to Avellaneda and Lipkin (2009) it is likely that these spikes in the lending rate can be considered as hard-to-borrow stocks and potentially ETF prices will be impacted as well.

Tables 2 and 3 present summary statistics for the log-differences of the ETF prices and lending rates of the seven series considered. For price returns (Table 2), the excess kurtosis are significant at $1 \%$. For the lending rates (Table 3 ), the skewness and the excess kurtosis are also significant at $1 \%$ for all ETFs.

18 The lending rates were obtained from an important broker-dealer in the USA.

${ }^{19} \mathrm{SPY}$ is one of the largest and most heavily-traded ETFs in the world, offering exposure to one of the most well known equity benchmarks, S\&P 500. 
Table 1. Description of Exchange-Traded Funds in our sample Asset Under Management (AUM) as of 16 April 2012.

\begin{tabular}{llcclr}
\hline \multirow{2}{*}{ Name } & Manager & $\begin{array}{c}\text { Leverage } \\
\text { Ratio }\end{array}$ & Ticker & Index/Sector & AUM \\
\hline EM Bull 3X Shares & Direxion & $3 \mathrm{X}$ & EDC & MSCI Emerging Markets & $\$ 368.16 \mathrm{M}$ \\
EM Bear 3X Shares & Direxion & $-3 \mathrm{X}$ & EDZ & MSCI Emerging Markets & $\$ 145.38 \mathrm{M}$ \\
MSCI Emerging & Ishares & N/A & EEM & MSCI Emerging Markets & $\$ 38.18 \mathrm{~B}$ \\
Ultra Financials ETF & ProShares & $2 \mathrm{X}$ & UYG & Financial & $\$ 896.02 \mathrm{M}$ \\
Ultrashort Financials & ProShares & $-2 \mathrm{X}$ & SKF & Financial & $\$ 234.82 \mathrm{M}$ \\
Financial Bull 3X Shares & Direxion & $3 \mathrm{X}$ & FAS & Russel 1000 Financial Serv. & $\$ 1.60 \mathrm{~B}$ \\
Financial Bear 3X Shares & Direxion & $-3 \mathrm{X}$ & FAZ & Russel 1000 Financial Serv. $\$ 737.19 \mathrm{M}$ \\
\hline
\end{tabular}

Table 2. Summary statistics on the LOG-PRice Differences of Daily Spot PRICES FOR EXCHANGE-TRADED FundS

There are 513 observations; they cover the period extending from 26 June 2009 to 8 August 2011. Following Campbell, Lo, and MacKinlay (1997, pp.18-20), the distributions of skewness and excess kurtosis under normality may be approximated as $\mathcal{N}(0,6 / T)$ and $\mathcal{N}(0,24 / T)$, respectively. For a sample size of 513 , the corresponding $1 \%$ critical points for skewness and excess kurtosis are thus \pm 0.252 and \pm 0.503 . We see that the excess kurtosis are significant at $1 \%$ for all ETFs returns.

\begin{tabular}{lccccccc}
\hline & EDC & EDZ & EEM & UYG & SKF & FAS & FAZ \\
\hline Mean & 0.0027 & -0.0031 & 0.0010 & 0.0015 & -0.0016 & 0.0021 & -0.0024 \\
Standard deviation & 0.0445 & 0.0458 & 0.0155 & 0.0292 & 0.0293 & 0.0433 & 0.0434 \\
Skewness & -0.0453 & -0.0112 & 0.0038 & -0.0464 & 0.0730 & -0.0675 & 0.0681 \\
Excess kurtosis & 1.5760 & 1.3661 & 1.7113 & 1.3813 & 1.3798 & 1.3660 & 1.7752 \\
\hline
\end{tabular}

Table 3. Summary Statistics ON DAILY LENDing RATES FOR ExChAnge-Traded FUNDS

There are 513 observations; they cover the period extending from 26 June 2009 to 8 August 2011. Based on Campbell, Lo, and MacKinlay (1997, pp.18-20), for a sample size of 513 , the corresponding $1 \%$ critical points for skewness and excess kurtosis are, respectively, \pm 0.252 and \pm 0.503 .

\begin{tabular}{lccccccc}
\hline & EDC & EDZ & EEM & UYG & SKF & FAS & FAZ \\
\hline Mean & 0.0324 & 0.0134 & 0.0239 & 0.0120 & 0.0056 & 0.0069 & 0.0143 \\
Standard deviation & 0.3030 & 0.1856 & 0.3296 & 0.1667 & 0.1196 & 0.1447 & 0.1788 \\
Skewness & 5.3971 & 6.7917 & 7.5914 & 2.7583 & 1.0000 & 2.9599 & 3.1353 \\
Excess kurtosis & 47.40 & 91.99 & 99.59 & 17.44 & 7.06 & 21.35 & 22.43 \\
\hline
\end{tabular}


The seven ETFs exhibit varying degree of volatility, positive and negative trend and cyclical patterns during the period considered. For example, visual inspection of Figure 2 indicates a downward trend common to these series but different frequencies of large price changes (greater than $5 \%$ in absolute value). In general all seven ETFs exhibit large negative and positive price changes that occur with different intensity, all of which is consistent with skewness and excess kurtosis indicated by the sample statistics in Table 2. A natural question is then to test whether jumps in the lending rates are transmitted to its prices.

The estimation results are presented in Table 4, we report estimates and standard errors, the LR test statistic and and $p$-values ${ }^{20}$ as proposed by Khalaf et al. (2003). A number of conclusions may be drawn from this table. First, we see that the geometric Brownian motion (GBM) model is rejected for all the LETF investigated. Indeed, the LR test based on bound-based $p$-values, indicates that for all series the null hypothesis of no-jump component can be rejected at $1 \%$ significance, which is consistent with finding in the extant empirical literature.

For the Merton model-i.e. if $\sigma_{2}=0$ and $\lambda_{0}=\theta$, then $\lambda_{t}=\theta$, for all $t$ in equation (7)-, estimated daily jump frequencies $\left(\lambda_{0}\right)$ are very similar and range from 0.036 (one jump every $\approx 27$ days) for FAS to 0.023 (one jump every $\approx 43$ days $)$ for EDC. Regarding the jump size parameters $\left(\mu_{Y}\right.$ and $\left.\sigma_{Y}\right)$ we observe a heterogeneous behavior for estimates of the mean jump sizes, $\mu_{Y}$, since that for four of the LETFs the estimative of the mean jump size is negative while that for three of them the mean size is positive. The existence of jumps on LETF have by itself important implications for options pricing and portfolio allocation, because in both cases we do not have a perfect hedge for options on those LETFs.

The parameter $\mu$ estimates the daily return generated by the continuous portion of the process and is accurately estimated for all indices. In all cases, a comparison with Table 2 indicates that $\mu$ is measuring only the continuous part, because when the jump size is negative (positive) $\mu$ is larger (smaller) than the sample mean.

In this paper we focus on estimation of a jump-diffusion model parameters using the borrow rate as a proxy for the non-observable stochastic intensity

20 The Monte-Carlo based test is performed as follows: (i) the likelihood ratio (LR) statistic is calculated for the observed sample, $L R_{0}$; (ii) $\mathrm{N}$ simulated samples are generated using draws from the null DGP; (iii) the LR statistic, $L R_{n}$, is calculated for each of the simulated samples, $1 \leq n \leq N$; (iv) The rank $\hat{R}_{N}\left(L R_{0}\right)$ of the observed sample $L R_{0}$ is determined in $L R_{0} \ldots L R_{N} ;(\mathrm{v})$ the MC $p$-value is obtained from $\hat{p}_{N}\left(L R_{0}\right)=1-\left(\hat{R}_{N}\left(L R_{0}\right)-1\right) /(N+1)$. 


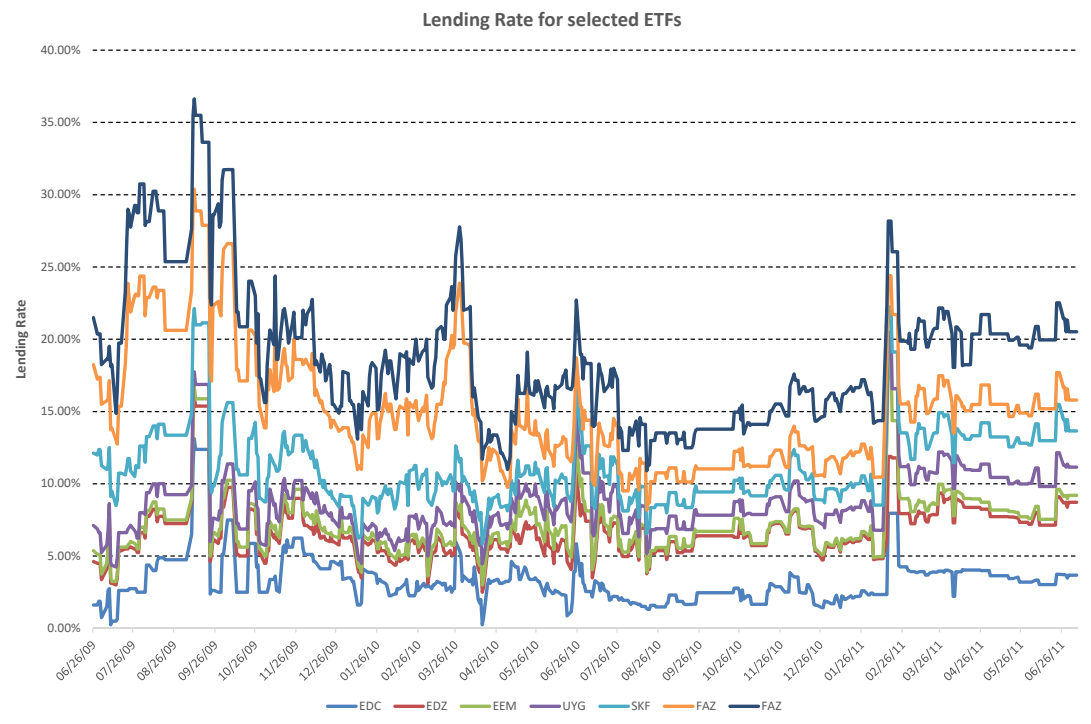

Figure 1. LENDING RATES

The lending rates are expressed in annual basis and computed as the average values for all transactions carried with the ETFs in our sample.

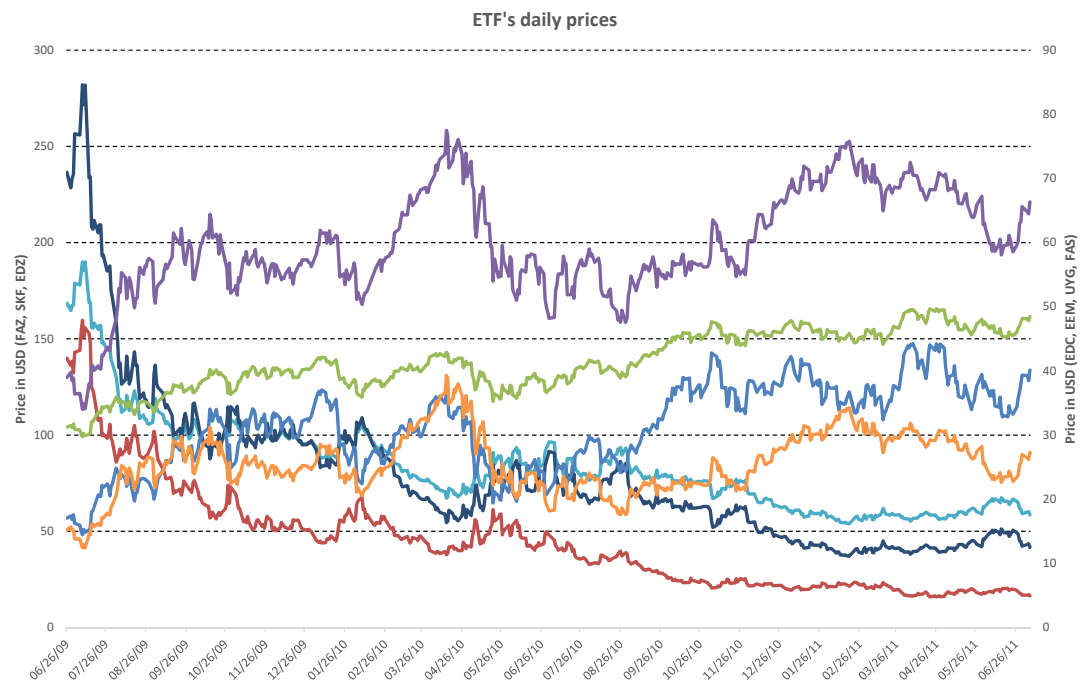

Figure 2. ETF'S DAILY PRICES

ETF prices are expressed in two axis: (i) left-hand side: FAZ, SKF and EDZ; (ii) righthand side: EDC, EEM, UYG and FAS. Prices are end of day values. 
Table 4. Estimation Results

Standard errors are in parenthesis. DSJD denotes double stochastic jump diffusion (extended Avellaneda \& Lipkin, 2009) based on (4) and (7), JD denotes the Merton model based on (23) and GBM represents the geometric Brownian motion without jumps based on $(24) . \mathcal{L}(\hat{\boldsymbol{\theta}})$ is the log-likelihood evaluated at the estimated coefficients. $L R=2\left(\sup \{\mathcal{L}(\boldsymbol{\theta} \mid x): \boldsymbol{\theta} \in \Theta\}-\sup \left\{\mathcal{L}(\boldsymbol{\theta} \mid x): \boldsymbol{\theta} \in \Theta_{0}\right\}\right)$. p-value represents the bound Monte-Carlo (BMC) test developed by Khalaf, Saphores, and Bilodeau (2003). For each ETF, we present two $p$-values, the first represents testing $H_{0}$ : JD against $H_{1}$ : DSJD, while the second $p$-value describes $H_{0}$ : GBM against $H_{1}$ : JD.

\begin{tabular}{|c|c|c|c|c|c|c|c|c|c|c|c|}
\hline ETF & & $\mu_{Y}$ & $\sigma_{Y}$ & $\mu$ & $\sigma$ & $\kappa$ & $\theta-\lambda_{0}$ & $\sigma_{2}$ & $\mathcal{L}(\hat{\boldsymbol{\theta}})$ & LR & $p$-value \\
\hline EDC & $\begin{array}{c}D S J D \\
J D \\
G B M\end{array}$ & $\begin{array}{c}-0.026 \\
(7.3 \mathrm{E}-03) \\
-0.013 \\
(3.4 \mathrm{E}-01)\end{array}$ & $\begin{array}{c}0.010 \\
(5.4 \mathrm{E}-03) \\
0.010 \\
(8.8 \mathrm{E}-04)\end{array}$ & $\begin{array}{c}0.0023 \\
(7.2 \mathrm{E}-04) \\
0.0025 \\
(8.8 \mathrm{E}-04) \\
0.0027 \\
(6.1 \mathrm{E}-04)\end{array}$ & $\begin{array}{c}0.038 \\
(8.1 \mathrm{E}-03) \\
0.048 \\
(5.2 \mathrm{E}-04) \\
0.045 \\
(1.24 \mathrm{E}-04)\end{array}$ & $\begin{array}{c}9.741 \\
(3.3 \mathrm{E}-01)\end{array}$ & $\begin{array}{c}0.060 \\
(5.3 \mathrm{E}-03) \\
0.023 \\
(8.3 \mathrm{E}-04)\end{array}$ & $\begin{array}{c}0.0212 \\
(7.4 \mathrm{E}-03)\end{array}$ & $\begin{array}{l}-9.699 \\
-12.119 \\
-15.654\end{array}$ & $\begin{array}{l}4.840 \\
7.070\end{array}$ & $\begin{array}{l}0.089 \\
0.010\end{array}$ \\
\hline EDZ & $\begin{array}{c}D S J D \\
J D \\
G B M\end{array}$ & $\begin{array}{c}-0.027 \\
(8.3 \mathrm{E}-03) \\
-0.027 \\
(2.1 \mathrm{E}-03)\end{array}$ & $\begin{array}{c}0.029 \\
(7.4 \mathrm{E}-03) \\
0.010 \\
(1.9 \mathrm{E}-03)\end{array}$ & $\begin{array}{c}-0.0028 \\
(7.2 \mathrm{E}-03) \\
-0.0029 \\
(5.7 \mathrm{E}-03) \\
-0.0031 \\
(5.1 \mathrm{E}-04)\end{array}$ & $\begin{array}{c}0.021 \\
(9.2 \mathrm{E}-03) \\
0.068 \\
(2.9 \mathrm{E}-02) \\
0.046 \\
(1.32 \mathrm{E}-04)\end{array}$ & $\begin{array}{c}9.785 \\
(9.7 \mathrm{E}-01)\end{array}$ & $\begin{array}{c}0.061 \\
(8.3 \mathrm{E}-03) \\
0.025 \\
(8.7 \mathrm{E}-03)\end{array}$ & $\begin{array}{c}0.0112 \\
(6.3 \mathrm{E}-03)\end{array}$ & $\begin{array}{l}-6.530 \\
-11.658 \\
-16.345\end{array}$ & $\begin{array}{l}10.254 \\
9.375\end{array}$ & $\begin{array}{l}0.010 \\
0.010\end{array}$ \\
\hline EEM & $\begin{array}{c}D S J D \\
J D \\
G B M\end{array}$ & $\begin{array}{c}0.017 \\
(8.8 \mathrm{E}-02) \\
0.020 \\
(2.4 \mathrm{E}-03)\end{array}$ & $\begin{array}{c}0.039 \\
(8.9 \mathrm{E}-03) \\
0.021 \\
(6.8 \mathrm{E}-04)\end{array}$ & $\begin{array}{c}0.0011 \\
(7.9 \mathrm{E}-03) \\
0.0020 \\
(3.4 \mathrm{E}-03) \\
0.0030 \\
(6.1 \mathrm{E}-04)\end{array}$ & $\begin{array}{c}0.028 \\
(8.9 \mathrm{E}-04) \\
0.008 \\
(8.9 \mathrm{E}-04) \\
0.016 \\
(1.51 \mathrm{E}-04)\end{array}$ & $\begin{array}{c}9.992 \\
(6.3 \mathrm{E}-02)\end{array}$ & $\begin{array}{c}0.076 \\
(8.4 \mathrm{E}-02) \\
0.023 \\
(6.2 \mathrm{E}-02)\end{array}$ & $\begin{array}{c}0.0204 \\
(8.6 \mathrm{E}-02)\end{array}$ & $\begin{array}{l}-8.890 \\
-9.192 \\
-15.921\end{array}$ & $\begin{array}{c}0.603 \\
13.458\end{array}$ & $\begin{array}{l}0.633 \\
0.010\end{array}$ \\
\hline UYG & $\begin{array}{c}D S J D \\
J D \\
G B M\end{array}$ & $\begin{array}{c}-0.056 \\
(5.3 \mathrm{E}-02) \\
-0.032 \\
(4.4 \mathrm{E}-03)\end{array}$ & $\begin{array}{c}0.018 \\
(3.4 \mathrm{E}-03) \\
0.037 \\
(7.1 \mathrm{E}-03)\end{array}$ & $\begin{array}{c}0.0015 \\
(2.7 \mathrm{E}-03) \\
0.0015 \\
(5.4 \mathrm{E}-03) \\
0.0015 \\
(6.9 \mathrm{E}-04)\end{array}$ & $\begin{array}{c}0.020 \\
(8.0 \mathrm{E}-04) \\
0.08 \\
(8.1 \mathrm{E}-03) \\
0.022 \\
(5.36 \mathrm{E}-05)\end{array}$ & $\begin{array}{c}6.991 \\
(3.7 \mathrm{E}-02)\end{array}$ & $\begin{array}{c}0.054 \\
(9.3 \mathrm{E}-02) \\
0.035 \\
(2.1 \mathrm{E}-01)\end{array}$ & $\begin{array}{c}0.0108 \\
(5.1 \mathrm{E}-02)\end{array}$ & $\begin{array}{c}-8.341 \\
-12.349 \\
-17.932\end{array}$ & $\begin{array}{c}8.016 \\
11.167\end{array}$ & $\begin{array}{l}0.068 \\
0.010\end{array}$ \\
\hline SKF & $\begin{array}{c}D S J D \\
J D \\
G B M\end{array}$ & $\begin{array}{c}0.025 \\
(1.4 \mathrm{E}-03) \\
0.110 \\
(2.7 \mathrm{E}-03)\end{array}$ & $\begin{array}{c}0.028 \\
(1.9 \mathrm{E}-03) \\
0.017 \\
(3.9 \mathrm{E}-04)\end{array}$ & $\begin{array}{c}-0.0026 \\
(1.8 \mathrm{E}-03) \\
-0.0020 \\
(1.6 \mathrm{E}-03) \\
-0.0016 \\
(4.6 \mathrm{E}-04)\end{array}$ & $\begin{array}{c}0.020 \\
(5.0 \mathrm{E}-03) \\
0.058 \\
(2.1 \mathrm{E}-03) \\
0.029 \\
(5.37 \mathrm{E}-04)\end{array}$ & $\begin{array}{c}7.987 \\
(1.3 \mathrm{E}-02)\end{array}$ & $\begin{array}{c}0.045 \\
(1.5 \mathrm{E}-03) \\
0.032 \\
(1.9 \mathrm{E}-03)\end{array}$ & $\begin{array}{c}0.0864 \\
(4.6 \mathrm{E}-03)\end{array}$ & $\begin{array}{l}-9.843 \\
-12.140 \\
-17.582\end{array}$ & $\begin{array}{c}4.595 \\
10.884\end{array}$ & $\begin{array}{l}0.105 \\
0.010\end{array}$ \\
\hline FAS & $\begin{array}{c}D S J D \\
J D \\
G B M\end{array}$ & $\begin{array}{c}0.030 \\
(6.7 \mathrm{E}-03) \\
0.024 \\
(9.2 \mathrm{E}-03)\end{array}$ & $\begin{array}{c}0.037 \\
(4.9 \mathrm{E}-03) \\
0.015 \\
(1.9 \mathrm{E}-03)\end{array}$ & $\begin{array}{c}0.0021 \\
(7.2 \mathrm{E}-04) \\
0.0031 \\
(1.4 \mathrm{E}-03) \\
0.0043 \\
(5.7 \mathrm{E}-04)\end{array}$ & $\begin{array}{c}0.030 \\
(2.4 \mathrm{E}-03) \\
0.028 \\
(1.8 \mathrm{E}-02) \\
0.043 \\
(1.18 \mathrm{E}-04)\end{array}$ & $\begin{array}{c}8.616 \\
(4.4 \mathrm{E}-01)\end{array}$ & $\begin{array}{c}0.070 \\
(2.1 \mathrm{E}-01) \\
0.036 \\
(1.0 \mathrm{E}-01)\end{array}$ & $\begin{array}{c}0.0520 \\
(3.2 \mathrm{E}-01)\end{array}$ & $\begin{array}{l}-8.345 \\
-12.119 \\
-16.222\end{array}$ & $\begin{array}{l}7.548 \\
8.205\end{array}$ & $\begin{array}{l}0.063 \\
0.010\end{array}$ \\
\hline FAZ & $\begin{array}{c}D S J D \\
J D \\
G B M\end{array}$ & $\begin{array}{c}0.031 \\
(1.6 \mathrm{E}-03) \\
0.043 \\
(1.5 \mathrm{E}-03)\end{array}$ & $\begin{array}{c}0.011 \\
(1.5 \mathrm{E}-03) \\
0.147 \\
(2.3 \mathrm{E}-03)\end{array}$ & $\begin{array}{c}-0.0035 \\
(1.5 \mathrm{E}-04) \\
-0.0028 \\
(6.2 \mathrm{E}-04) \\
-0.0024 \\
(6.6 \mathrm{E}-04)\end{array}$ & $\begin{array}{c}0.015 \\
(3.7 \mathrm{E}-03) \\
0.028 \\
(8.0 \mathrm{E}-04) \\
0.023 \\
(1.18 \mathrm{E}-04)\end{array}$ & $\begin{array}{c}7.993 \\
(5.4 \mathrm{E}-01)\end{array}$ & $\begin{array}{c}0.065 \\
(2.9 \mathrm{E}-03) \\
0.033 \\
(7.6 \mathrm{E}-03)\end{array}$ & $\begin{array}{c}0.0624 \\
(1.6 \mathrm{E}-03)\end{array}$ & $\begin{array}{l}-10.408 \\
-13.219 \\
-18.275\end{array}$ & 10.113 & 0.023 \\
\hline
\end{tabular}


to permit analysis of the impact of borrow rates on ETF prices. We see from Table 4 that the LR test computed via a bound-based $p$-values rejects the null hypothesis of pure Jump Diffusion (JD) in favor of a stochastic intensity jump model for two ETFs in our sample: FAZ and EDZ. As presented in Table 1, FAZ and EDZ are both bearish leverage ETF, with a relatively small AUM. Even though a small AUM may not be a necessary condition for including these ETF in a hard-to-borrow list, this fact may be relevant. Unfortunately, there is not enough variation on cross-section data for ETF asset under management that could be used to investigative this effect.

For both FAZ and EDZ, all parameters are significant at $1 \%$ level, but the estimates for two set of parameters are slightly different between these two LETFs. First, the mean jump size, $\mu_{Y}$ for EDZ is positive while for FAZ it is negative. Das and Sundaram (1999) derived ${ }^{21}$ closed-form expressions for skewness and kurtosis for jump-diffusion model. Mean of jump size, $\mu_{Y}$, determines skewness of distribution, while jump size volatility, $\sigma_{Y}$, controls the peakedness of the density, it is peaked for small values, but flat for large values. Using the estimates from Table 4 and the formula derived by Das and Sundaram (1999) we verify that the model (Kurtosis: $\mathrm{EDZ}=1.32$ and $\mathrm{FAZ}=1.4$; and skewness: $\mathrm{EDZ}=-0.42$ and $\mathrm{FAZ}=0.57)$ can match observed levels of skewness and kurtosis as presented in Table 2.

Although for these two ETFs we have mixed results on the sign of $\mu_{Y}$, these findings do not necessarily mean inconsistent estimation for two reasons. First, the model is able to match empirical skewness and kurtosis, and skewness of these two indices have indeed different signs. Second, given normally distributed jumps, the mean jump size has to accommodate both positive and negative values, an alternative would be specify a two-side distribution as proposed by Kou and Wang (2004) but that requires dealing with all complexity associated to it.

Second, the volatility of intensity process, $\sigma_{2}$, is also higher for FAZ. In particular, as standard in CIR process, the conditional volatility of the intensity process increases when the current level of borrow rate does. Moreover, according to equation (13) the jump probability is a positive function of $\sigma_{2}$. These two effects are in line with the jump clustering observed on the FAZ lending rate depicted in Figure 1. The other parameters estimates are very similar between

21 Excess Kurtosis $=3+\left[\frac{\lambda_{0}\left(\mu_{Y}^{4}+6 \mu_{Y}^{2} \sigma_{Y}^{2}+3 \sigma_{Y}^{4}\right)}{\left(\sigma^{2}+\lambda_{0} \sigma_{Y}^{2}+\lambda_{0} \mu_{Y}^{2}\right)^{2}}\right]$ and Skewness $=\left[\frac{\lambda_{0}\left(\mu_{Y}^{3}+3 \mu_{Y} \sigma_{Y}^{2}\right)}{\left(\sigma^{2}+\lambda_{0} \sigma_{Y}^{2}+\lambda_{0} \mu_{Y}^{2}\right)^{3} / 2}\right]$. 
these two indices.

The stochastic process describing the jump intensity, i.e equation (7), is a stationary mean reversion process. It can be stated then that $\theta$ is the equilibrium level for this stochastic differential equation. In a finite-time horizon, $\theta$ plays the role of attractor in the sense that when $\lambda_{t}>\theta$ the trend term $\kappa\left(\theta-\lambda_{t}\right)<0$, and therefore, $\lambda_{t}$ decreases and when $\lambda_{t}<\theta$ a similar argument establishes that $\lambda_{t}$ grows. Another key property of a mean-reverting process is the half-life $t_{1 / 2}=\ln (2) / \kappa$. This is the time taken for the process to revert half way to its long-term level from its current level. We have that for EDZ, the mean reversion rate of $\kappa=5$ for its intensity means that the $\lambda_{t}$ tends to be pulled back to its long-term level over a period of roughly 18 days. In turn, FAZ is little slower, it will take roughly 21 days to revert to its long-term mean.

In general we do not find enough statistical evidence supporting that LETF prices are affected by borrow rate, except for two cases. Although the hard to borrow effect has not been found significant for all ETF in our sample, its existence can not be ignored by market participants, in particular for options market makers. The reason is that shorting costs money and the arbitrage between puts and calls on the same line, known as a conversion, cannot be made unless there is stock available to short. Therefore, since synthetic puts cannot be manufactured by owning calls and shorting stock, the nominal put-call parity does not hold.

On the other hand, we do find statistical evidence supporting the presence of jumps (state dependent or not) for all ETFs in our sample. As already highlighted by Aït-Sahalia (2004) the study of jumps is relevant for investors in terms of asset allocation and portfolio optimization as large price movements may generate significant losses and encourage the demand for higher risk premia. After all, this paper contributes to the literature by presenting evidences aligned with Johannes et al. (1999) that jumps are not fully state independent and they can cause negative impacts on trading strategies of short sellers and options market makers alike.

\section{Final Remarks}

Securities lending is common theme in finance, mainly because it is tied to short-selling's practices and regulators have often alleged that a practice of short selling magnifies the decline of asset prices. But that is not the whole picture, because it ignores several risks involved on these strategies. Among others, 
there is hidden risk for loans without a guaranteed term, because under a recall notice the short seller, whether intentionally or not, will need to cover the short position in a rising market. This effect is magnified for a hard to borrow stock that is, if it is difficult to locate shareholders who are willing to lend the share.

Therefore, a hard-to-borrow stock can be seen as a security that presents an increased likelihood of buy-ins. In turn, the buy-in events may potentially introduce discontinuous movements in the asset prices as result of a sharp increase in its demand by short-seller seeking to cover a short position. In this sense, the occurrence of jumps are no longer unobservable, but could be identified with buy-in events.

The impact of jumps in asset prices have been studied systematically since Merton (1976). Recently some authors have tried to associate the occurrence of jumps with observable variables. In this paper we implement an econometric model to empirically test the hard-to-borrow model of Avellaneda and Lipkin (2009) for a selected group of Leveraged ETF. Our identification strategy relies on no-arbitrage arguments to connect the jump intensity with the lending rate. We do find statistical evidence supporting the hard-to-borrow model for two bearish three times leveraged ETF. Furthermore, as a by-product, we find that jumps are presented in all LETF in our sample. We view our results in this paper as a motivation for formulating possibly more involved jump models which are state dependent. A possible extension of this work could be to investigate whether the hard-to-borrow model works better using intraday prices or a different asset class.

\section{References}

Abreu, D., \& Brunnermeier, M. K. (2002). Synchronization risk and delayed arbitrage. Journal of Financial Economics, 66(2-3), 341-360. http:// dx.doi.org/10.1016/S0304-405X(02)00227-1

Aït-Sahalia, Y. (2002). Maximum likelihood estimation of discretely sampled diffusions: A closed-form approximation approach. Econometrica, 70(1), 223-262. http://dx.doi.org/10.1111/1468-0262.00274

Aït-Sahalia, Y. (2004). Disentangling diffusion from jumps. Journal of Financial Economics, 74(3), 487-528. http://dx.doi.org/10.1016/j.jfineco.2003.09 .005

Aït-Sahalia, Y. (2008). Closed-form likelihood expansions for multivariate diffusions. The Annals of Statistics, 36(2), 906-937. Retrieved from https://www.jstor.org/stable/25464650 
Andrews, D. W. K. (2000). Inconsistency of the bootstrap when a parameter is on the boundary of the parameter space. Econometrica, 68(2), 399-405. http://dx.doi.org/10.1111/1468-0262.00114

Andrews, D. W. K. (2001). Testing when a parameter is on the boundary of the maintained hypothesis. Econometrica, 69(3), 683-734. http:// dx.doi.org/10.1111/1468-0262.00210

ASIC - Australian Securities and Investments Commission. (2008, October). Regulatory guide 196: Short selling. Victoria, Australia. Retrieved from https://download.asic.gov.au/media/4896780/rg196-published-8 -october-2018.pdf (Superseded Regulatory Guide 196, issued 19 September 2008)

Avellaneda, M., \& Lipkin, M. (2009). A dynamic model for hard-to-borrow stocks. Risk Magazine(June), 92-97.

Black, F., \& Scholes, M. (1973). The pricing of options and corporate liabilities. Journal of Political Economy, 81(3), 637-654. http://dx.doi.org/10.1086/ 260062

Boehmer, E., \& Wu, J. (2013). Short selling and the price discovery process. Review of Financial Studies, 26(2), 287-322. http://dx.doi.org/10.1093/ $\mathrm{rfs} / \mathrm{hhs} 097$

Bollen, N. (1997). Derivatives and the price of risk. The Journal of Futures Markets, 17(7), 839-854. http://dx.doi.org/10.1002/(SICI)1096 -9934(199710) 17:7<839::AID-FUT6>3.0.CO;2-O

Brandt, M. W., \& Santa-Clara, P. (2002). Simulated likelihood estimation of diffusions with an application to exchange rate dynamics in incomplete markets. Journal of Financial Economics, 63(2), 161-212. http:// dx.doi.org/10.1016/S0304-405X(01)00093-9

Bremaud, P. (1981). Point processes and queues: Martingale dynamics. Berlin: Springer-Verlag.

Broadie, M., Chernov, M., \& Johannes, M. (2007). Model specification and risk premia: Evidence from futures options. Journal of Finance, 62(3), 1453-1490. http://dx.doi.org/10.1111/j.1540-6261.2007.01241.x

Campbell, J. W., Lo, A. W., \& MacKinlay, A. C. (1997). The econometrics of financial markets. Princeton, NJ: Princeton University Press.

Chague, F., De-Losso, R., De Genaro, A., \& Giovannetti, B. (2014). Short-sellers: Informed but restricted. Journal of International Money and Finance, 47, 56-70. http://dx.doi.org/10.1016/j.jimonfin.2014.04.001

Cont, R., \& Tankov, P. (2003). Financial modeling with jump processes. Chapman \& Hall.

Das, S. R., \& Sundaram, R. K. (1999). Of smiles and smirks: A term structure perspective. The Journal of Financial and Quantitative Analysis, 34(2), 211-239. http://dx.doi.org/10.2307/2676279 
Davies, R. B. (1977). Hypothesis testing when a nuisance parameter is present only under the alternative. Biometrika, 64(2), 247-254. http://dx.doi.org/ $10.2307 / 2335690$

Davies, R. B. (1987). Hypothesis testing when a nuisance parameter is present only under the alternative. Biometrika, 74(1), 33-43. http://dx.doi.org/ $10.2307 / 2336019$

D'Avolio, G. (2002). The market for borrowing stock. Journal of Financial Economics, 66(2-3), 271-306. http://dx.doi.org/10.1016/S0304-405X(02) 00206-4

De Genaro, A., \& Avellaneda, M. (2018). Pricing interest rate derivatives under monetary changes. International Journal of Theoretical and Applied Finance, 21(6), 723-748. http://dx.doi.org/10.1142/S0219024918500371

De Genaro, A., \& Simonis, A. (2015). Estimating doubly stochastic Poisson process with affine intensities by Kalman filter. Statistical Papers, 56(3), 723-748. http://dx.doi.org/10.1007/s00362-014-0606-6

Diamond, D. W., \& Verrecchia, R. E. (1987). Constraints on short-selling and asset price adjustment to private information. Journal of Financial Economics, 18(2), 277-311. http://dx.doi.org/10.1016/0304-405X(87) 90042-0

Duffie, D., Gârleanuc, N., \& Pedersen, L. H. (2002). Securities lending, shorting, and pricing. Journal of Financial Economics, 66(2-3), 307-339. http:// dx.doi.org/10.1016/S0304-405X(02)00226-X

Dufour, J.-M. (1997). Some impossibility theorems in econometrics with applications to structural and dynamic models. Econometrica, 65(6), 1365-1387. http://dx.doi.org/10.2307/2171740

Dufour, J.-M. (2006). Monte Carlo tests with nuisance parameters: A general approach to finite-sample inference and nonstandard asymptotics in econometrics. Journal of Econometrics, 133(2), 443-477. http://dx.doi.org/ 10.1016/j.jeconom.2005.06.007

Dufour, J.-M., \& Khalaf, L. (2001). Monte Carlo test methods in econometrics. In B. H. Baltagi (Ed.), A companion to theoretical econometrics (pp. 494-519). Blackwell.

Durham, G. B., \& Gallant, A. R. (2002). Numerical techniques for maximum likelihood estimation of continuous-time diffusion processes. Journal of Business 86 Economic Statistics, 20(3), 297-316. http://dx.doi.org/ 10.1198/073500102288618397

Eberlein, E., \& Keller, U. (1995). Hyperbolic distributions in finance. Bernolli, 1(3), 281-299. http://dx.doi.org/10.2307/3318481

Elerian, O. (1998). A note on the existence of a closed form conditional transition density for the Milstein scheme (Economics Discussion Paper No. 1998-W18). University of Oxford, Nuffield College. Retrieved from http://www.nuff.ox.ac.uk/economics/papers/1998/milpaper.pdf 
Eraker, B. (2004). Do stock prices and volatility jump? Reconciling evidence from spot and option prices. Journal of Finance, 59(3), 1367-1403. http:// dx.doi.org/10.1111/j.1540-6261.2004.00666.x

Evans, R. B., Geczy, C. G., Musto, D. K., \& Reed, A. V. (2009). Failure is an option: Impediments to short selling and options prices. The Review of Financial Studies, 22(5), 1955-1980. http://dx.doi.org/10.1093/rfs/ $\mathrm{hhm} 083$

G30 - Group of Thirty. (2003). Global clearing and settlement: A plan of action. Washington, DC: Group of Thirty. Retrieved from http://group30.org/ images/uploads/publications/G30_GlobalClearingSettlement.pdf

Goldfeld, S. M., \& Quandt, R. E. (1972). Nonlinear methods in econometrics. North-Holland.

Hamilton, J. D. (1994). Time series analysis. Princeton University Press.

Hansen, B. E. (1996). Inference when a nuisance parameter is not identified under the null hypothesis. Econometrica, 64(2), 413-430. http://dx.doi.org/ $10.2307 / 2171789$

Johannes, M., Kumar, R., \& Polson, N. G. (1999). State dependent jump models: How do US equities indices jump? Retrieved from https://www0.gsb .columbia.edu/mygsb/faculty/research/pubfiles/566/sdj.pdf

Kaneko, H., \& Nakao, S. (1988). A note on approximation for stochastic differential equations. Séminaire de Probabilités de Strasbourg, 22, 155-162. Retrieved from http://eudml.org/doc/113627

Karatzas, I., \& Shreve, S. E. (1991). Brownian motion and stochastic calculus. Berlin: Springer.

Khalaf, L., Saphores, J.-D., \& Bilodeau, J.-F. (2003). Simulation-based exact jump tests in models with conditional heteroskedasticity. Journal of Economic Dynamics 8 Control, 28, 531-553. http://dx.doi.org/10.1016/ S0165-1889(03)00034-4

Kiefer, N. M. (1978). Discrete parameter variation: Efficient estimation of switching regression model. Econometrica, 46(2), 427-434. http:// dx.doi.org/0012-9682(197803)46:2<427:DPVEEO>2.0.CO;2-I

Kloeden, P. E., \& Platen, E. (1999). Numerical solution of stochastic differential equations. Springer-Verlag.

Kou, S. G., \& Wang, H. (2004). Option pricing under a double exponential jump diffusion model. Management Science, 50(9), 1178-1192. http:// dx.doi.org/10.1287/mnsc. 1030.0163

Lamont, O. A. (2004). Short sale constraints and overpricing. In F. J. Fabozzi (Ed.), Short selling: Strategies, risks, and rewards (pp. 179-203). Wiley.

Lewis, R. M., Torczon, V., \& Trosset, M. W. (2000). Direct search methods: Then and now. Journal of Computational and Applied Mathematics, 124(1-2), 191-207. http://dx.doi.org/10.1016/S0377-0427(00)00423-4 
Li, C. (2013). Maximum-likelihood estimation for diffusion processes via closedform density expansions, the. Annals of Statistics, 41(3), 1350-1380.

Merton, R. C. (1976). Option pricing when underlying stock returns are discontinuous. Journal of Financial Economics, 3(1-2), 125-144. http:// dx.doi.org/10.1016/0304-405X(76)90022-2

Michalewicz, Z. (1996). Genetic algorithms + data structures = evolution programs. New York: Springer-Verlag.

Pedersen, A. R. (1995). A new approach to maximum likelihood estimation for stochastic differential equations based on discrete observations. Scandinavian Journal of Statistics, 22(1), 55-71. Retrieved from https://www.jstor.org/stable/4616340

Piazzesi, M. (2005). Bond yields and the Federal Reserve. Journal of Political Economy, 113(2), 311-344. http://dx.doi.org/10.1086/427466

Prakasa Rao, B. L. S. (1999). Semimartingales and their statistical inference. Chapman \& Hall/CRC. (Monographs on Statistics and Applied Probability 83)

Prause, K. (1999). The generalized hyperbolic model: Estimation, financial derivatives, and risk measures (PhD Dissertation, Albert-LudwigsUniversität Freiburg). Retrieved from https://freidok.uni-freiburg.de/ $\mathrm{dnb} /$ download/15

Saffi, P. A. C., \& Sigurdsson, K. (2011). Price efficiency and short selling. The Review of Financial Studies, 24(3), 821-852. http://dx.doi.org/10.1093/ $\mathrm{rfs} / \mathrm{hhq} 124$

Sato, K.-I. (1999). Lévy process and infinitely divisible distributions. Cambridge University Press. (Cambridge Studies in Advanced Mathematics 68)

Self, S. G., \& Liang, K.-Y. (1987). Asymptotic properties of maximum likelihood estimators and likelihood ratio tests under nonstandard conditions. Journal of American Statistician Association, 82(398), 605-610. http://dx.doi .org/10.2307/2289471

Stramer, O., \& Yan, J. (2007). Asymptotics of an efficient Monte Carlo estimation for the transition density of diffusion processes. Methodology and Computing in Applied Probability, 9, 483-496. http://dx.doi.org/ $10.1007 / \mathrm{s} 11009-006-9006-2$

Yamada, T. (1978). Sur une construction des solutions d'equations différentielles stochastiques dans le cas non-lipschitzien. In C. Dellacherie, P. A. Meyer, \& M. Weil (Eds.), Séminaire de probabilités XII (pp. 114-131). SpringerVerlag. (Lecture Notes in Mathematics, vol.649) http://dx.doi.org/ 10.1007/BFb0064599 


\section{Appendix A Additional graphics}
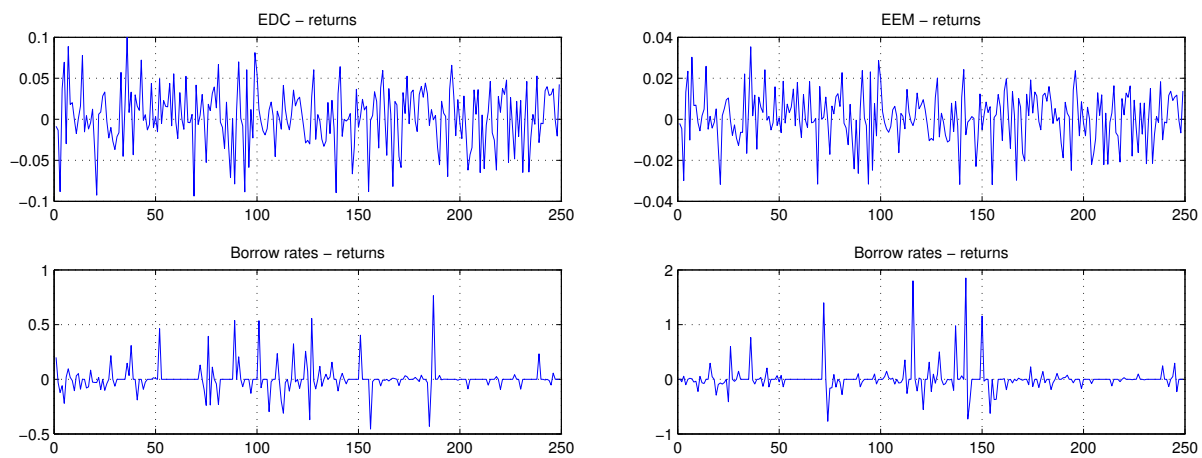

(a) EDC

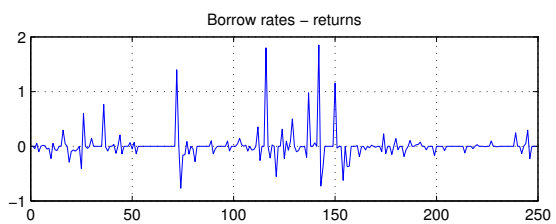

(b) EEM
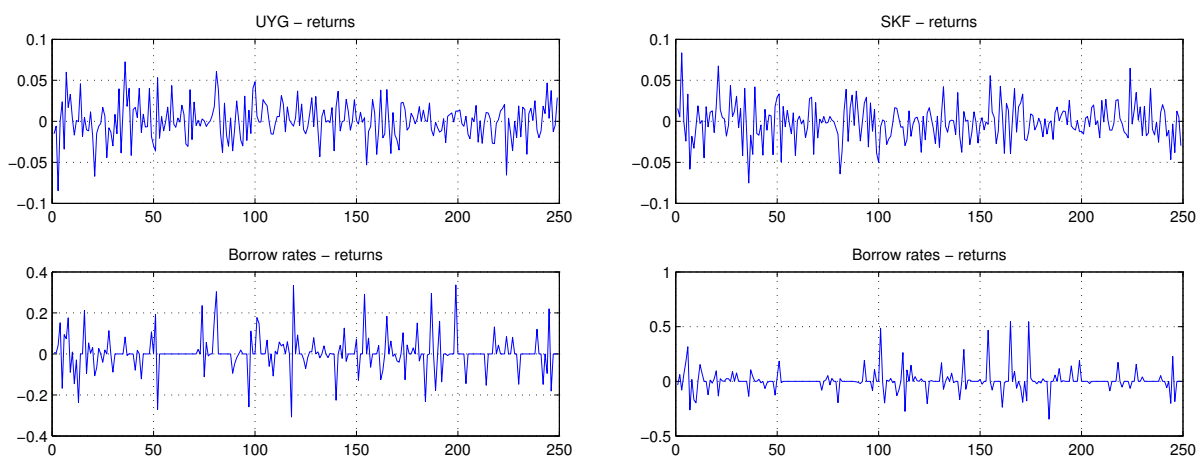

(c) UYG

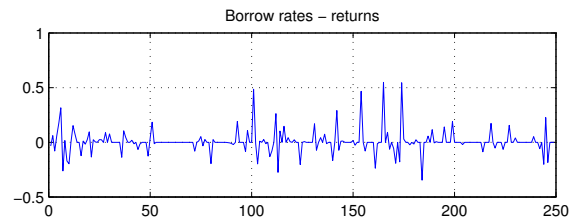

(d) SKF
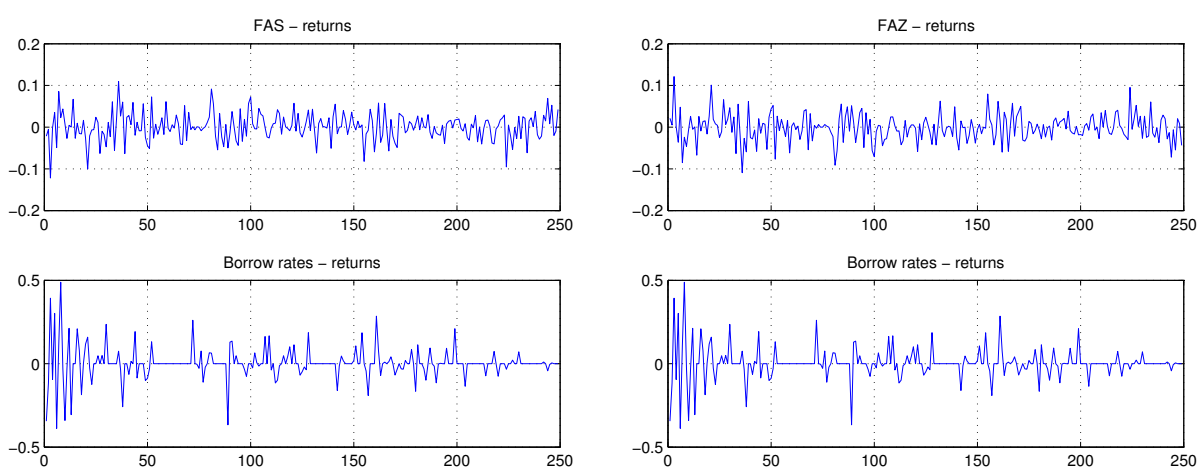

(e) FAS

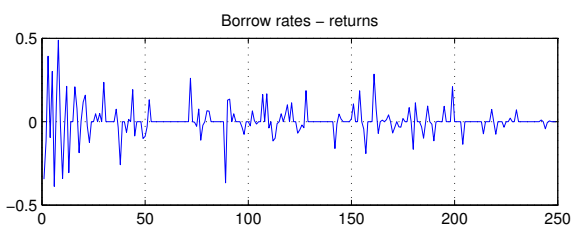

(f) FAZ

Figure 3. REtURnS AND BORROW RATES 